\title{
AN INTERACTIVE DECISION SUPPORT METHOD FOR REAL ESTATE MANAGEMENT IN A MULTI-CRITERIA FRAMEWORK - REMIND
}

\author{
Franck TAILLANDIER ${ }^{a, *}$, Irène ABI-ZEID ${ }^{b}$, Patrick TAILLANDIER ${ }^{c}$, \\ Gérard SAUCE d, Régis BONETTO e \\ a Université Bordeaux 1, I2M-GCE, UMR CNRS 5295, 351 cours de la Libération, Bat A11, 33405 \\ Talence Cedex, France \\ b CERMID, Faculté d'administration, Université Laval, 2325, rue de la Terrasse, Québec, GoV 1A6, \\ Canada \\ ${ }^{c}$ Université de Rouen, MTG Lab., UMR-IDEES 6228, 1, rue Thomas Becket, 76821 Mont-Saint-Aignan, \\ France \\ ${ }^{d}$ STERN, Villantipolis 7, 473, route des Dolines, 06560 Valbonne, Sophia-Antipolis, France \\ e Centre Scientifique et Technique du Bâtiment (CSTB), Département TIDS, 290, route des Lucioles BP \\ 209, 06904 Sophia Antipolis Cedex, France
}

Received 10 July 2012; accepted 21 June 2013

\begin{abstract}
Managing a housing stock involves complex decision making such as the design of a multiyear action plan pertaining to the maintenance and upgrading of the properties. In order to address this problem, we developed a novel interactive decision support method (REMIND) to assist a housing stock manager in the progressive design and choice of a multiyear action plan based on multiple criteria. It uses a filtering approach both at the individual action level and at the global scenario level where the housing stock manager can gradually express preferences and conduct what-if analyses. An optimization component based on Tabu search allows the decision-maker to obtain a set of good plans from which he can choose the one to implement. The quality of a plan is defined in terms of how well it meets the goals on each criterion. The application of the method was tested in a leading French property management company.
\end{abstract}

KEYWORDS: Decision support; Multiyear action plan; Simulation; Strategic housing stock management; Optimization

\section{INTRODUCTION}

The strategic management of a housing stock involves complex decision making such as the multiyear planning and scheduling of a set of improvement actions pertaining to the maintenance and upgrading of the properties. The main challenge for manager is to choose and to schedule, over a multiyear horizon, a subset of actions recommended by technical experts, subject to constraints such as limited financial and human resources (Taillandier et al. 2009b). Many steps are involved in this strategic planning process, namely the choice of the appropriate actions to implement, the scheduling of the chosen actions, the design of

\footnotetext{
* Corresponding author. E-mail: franck.taillandier@u-bordeaux1.fr
}

good scenarios or action plans and finally the selection of the best action plan to implement.

In order to address this situation, we developed a novel interactive dynamic decision support method to assist a housing stock manager in the progressive design and choice of a multiyear action plan. We divided the process into four main phases: system modeling, retaining or excluding individual actions using filters, generating a set of good scenarios using an optimization approach, and finally selecting, among the scenarios, the action plan to be implemented.

The method was implemented in a prototype and applied in an experiment conducted in collaboration with a leading French company. An application of the method is presented in section 3 . 


\section{METHOD DESCRIPTION}

\subsection{Overview of the decision support method}

An earlier simplified version of the proposed method was used by a housing stock manager as described in Taillandier et al. (2009b). However, it focused on individual properties on a yearly basis and did not allow for a global multiyear view of the housing stock. Furthermore, it did not contain provisions for obtaining an optimal global scenario. The lessons learned from this first experiment allowed us to develop, REMIND (Real Estate Management INteractive Decision), the multicriteria decision support method described in this paper.

\subsubsection{An interactive multicriteria approach}

Managing a housing stock involves multiple objectives that are often conflicting: maximizing the number of properties available for rent, ensuring a high level of security, providing a good level of comfort, minimizing maintenance costs, minimizing upgrade costs, etc. We therefore opted for a multicriteria approach in order to avoid the amalgamation of the various dimensions into a single value function (Taillandier et al. 2009a). Several arguments can be made in favor of a multi-criteria approach (Bouyssou 1993). A first argument is the ability to take into account, explicitly, various aspects of the impact of an action (Roy 1985). It is very difficult to arrive to a common understanding of the concrete consequences of an action, when different dimensions are amalgamated in a single criterion as is the case in single criterion approaches. A second argument in favor of a multi-criteria approach is the increased ability to capture along each dimension, the elements of uncertainty, vagueness, and imprecision of the data, thus avoiding the cumulative effects of errors. Finally, a multicriteria approach, through its explicit and transparent nature, favors a better understanding of the compromises inherent to all decisions.

Multicriteria decision analysis has been applied in a variety of areas including location problems (Nickel et al. 2005), finance (Spronk et al. 2005), energy planning (Diakoulaki et al. 2005), telecommunication network planning and design (Climaco, Craveirinha 2005), sustainable development (Munda 2005), water resources management (Hajkowicz, Collins 2007), and nuclear emergencies, (Mustajoki et al. 2007). In particular, there are numerous multicriteria decision support systems using interactive approaches (Korhonen 2005; Miettinen et al. 2008). However, in most of these approaches, the alternatives are assumed to be already available and defined either explicitly or implicitly by means of a mathematical model. Furthermore, it is often assumed that the criteria are quantitative (Narula et al. 2003; Trinkaus, Hanne 2005) and sometimes a stochastic component is present (Nowak 2006). This is not the case for the problem of property management that we address in this paper, where we adopt a constructive scenario-based approach aimed at designing acceptable scenarios rather than evaluating predefined alternatives (Stewart, Scott 1995). This is similar to constructing a portfolio of activities where the objective is to select a subset of activities with the best overall value for a given budget (Phillips, Bana e Costa 2007; Montibeller et al. 2009).

The method we designed is based on an interactive approach where the housing manager gradually expresses his preferences to define feasible solutions based on multiple criteria. A planning scenario is a combination of feasible actions scheduled in time and corresponds to a "composite alternative" in the decision making process. A solution is the scenario or action plan selected for implementation. We opted for a filter-based approach that allows to discriminate between actions (at a local level) - or between scenarios (at a global level) based on specific criteria such as regulatory compliance or costs. The decision maker can thus express his preferences in order to build and evaluate feasible alternatives, using both quantitative and qualitative criteria. Furthermore, he can see the impact of his expressed preferences, modify, or validate the retained actions. In addition, he may rewind at any time to test new filters and to generate other alternatives. This filtering approach may allow for a better acceptance of the decision by other actors since it keeps track of the rationale behind the process.

\subsubsection{The weights issue}

Many decision support methods require the elicitation of weights for the various criteria. In some of these methods, the weights are actually technical parameters and do not necessarily reflect the relative importance or criteria. Eliciting weights is often a difficult task although there are many methods to do so (Bana e Costa 1986; Keeney, Raiffa 1976; Kodikara et al. 2010; Yeh et al. 1999). Furthermore, it is often a challenge to obtain precise weights with limited variability and uncertainty (Churchman, Ackoff 1954; Gershon 1984; Schärlig 1985; Vansnick 1986). In addition, preferences and the relative importance of the criter- 
ia may change as a function of the performance level attained (Taillandier, Abi-Zeid 2013). For example, the security aspect may be considered to be very important up to a certain point, after which it becomes secondary once the baseline has been achieved. Also, when the impact of the various trade-offs is not fully understood, it may be difficult to express genuine preferences.

This raises a second problem with preferences. For many decision problems, preference of one criterion over another can be stable for an individual. However, there are situations where it is not the case (Schärlig 1985). This is quite common when a set of actions must be chosen to constitute a scenario (the case for housing stock management) as opposed to a single action scenario. For example, one can focus on the environmental aspect in a given geographical area, while this aspect is not as important in other areas. Similarly, the quality of service provided in a given building may be considered important prior to a deadline such as the signing of a new lease and less important afterwards. For these reasons, we chose not to include criteria weights in our method.

\subsubsection{Main phases of the method}

The four main phases of the REMIND method are presented in Figure 1. The first phase is to model the system by defining the parameters and constraints and assessing candidate actions in terms of their potentially positive impact on a building's state. We use the multi-criteria evaluation approach proposed in (Taillandier et al. 2009a) that uses simulation to assess the impact of an action in terms of possible increases or decreases in criteria values. The impact of an action is then obtained by comparing the building's state following an action's implementation with the anticipated building's state if no action were implemented.

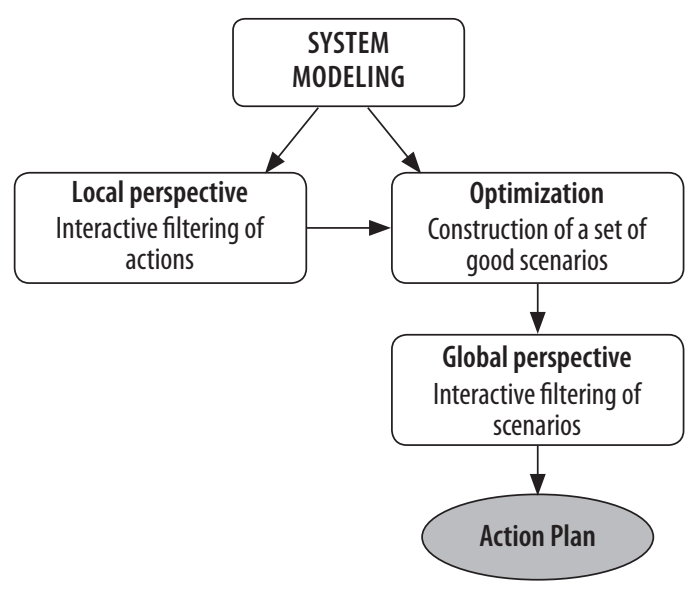

Fig. 1. The four phases of the decision support method
The second phase is to build an initial partial scenario from a local perspective on an individual action basis. By local perspective, we mean according to precise goals on a given element (for example, ensure a high security level on a given building). The local perspective aims at helping the housing manager identify key actions, i.e. actions that appear to be particularly important because they respond to an emergency, because they are integrated into his strategy, or because they seem particularly efficient in the context. In this phase, the decision maker can reject actions that he does not wish to implement. This is achieved through a filtering approach that puts him at the heart of the decision process and allows him to exclude what is unacceptable and to favor what seems essential to him. The retained actions are subsequently scheduled in time as a function of the constraints, thereby generating an initial partial scenario engulfing the minimal expectations of the decision-maker.

In the third phase, we complete the initial partial scenario with the remaining actions (actions that were not selected or rejected at the local level) and construct complete scenarios that meet the constraints. The difficulty resides in the large number of possible scenarios that may be generated. It is not realistic to expect an individual, without external help, to generate all the possible scenarios, compare them, and understand the implications of choosing one over another. For this reason, we developed an optimization algorithm based on Tabu search that generates a set of good scenarios. The performance of a scenario is defined by how closely it meets the expressed goals of the housing manager and how close it is to an ideal scenario defined by him.

Finally, in the last phase, various filters are used to explore and sort through the set of good scenarios from the previous phase (global perspective) in order to select the action plan (best scenario) that will be implemented.

\subsection{Workings of the method}

The main ingredients of REMIND consist of input data and a preference model (Fig. 2). Data include a description of the housing stock, the planning time horizon, budget constraints (or other types of constraints), a list of eligible actions recommended by technical experts and their respective costs. The preference model includes a set of criteria that are used to assess actions based on their anticipated impact on buildings (Taillandier et al. 2009a). The 


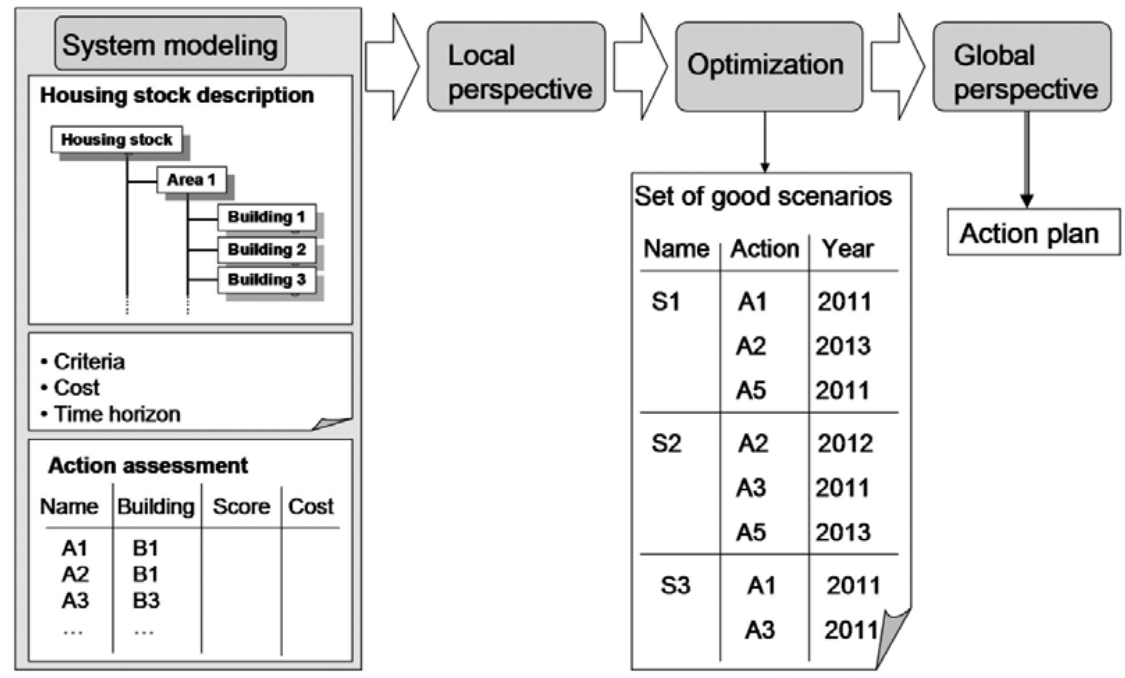

Fig. 2. Design of an action plan

output of the local perspective and the optimization phases are a set of scenarios that are later filtered on a global perspective in order to obtain the action plan.

\subsubsection{System modeling}

System modeling requires the definition of system elements, time horizon and the assessment of the current state of the housing stock, as the well as the impact of proposed actions. System elements are defined by a hierarchical description of the components of the real estate park. For example a four-level description (Park-Area-Building-Component) could be chosen. The housing manager is often interested in a strategic planning over many years (Bonetto, Sauce 2006). However, the longer the time horizon, the more uncertainty is involved, and the more complex the method becomes since the number of feasible scenarios can grow exponentially.

An important task in system modeling is the assessment of the present state of a housing stock as well as the future state in the absence of any remedial interventions. The definition of the evaluation criteria and their scales is a crucial step. Indeed, they are key elements in the assessment and decision. The family of criteria must be coherent, i.e. meets requirements of exhaustiveness, cohesion and non-redundancy (Hites et al. 2006). This can only be accomplished through discussions between the stakeholders including the housing manager, and the technical experts. The criteria will vary depending on the kind of company and the type of real estate park, since they must reflect the interests and the preferences of the individuals as well as the company's strategy. Many multi-cri- teria methods assume independence among criteria and commensurability. The commensurability condition poses no problem in our case: the criteria are all expressed on an identical scale. We use a qualitative assessment where each value on the scale is clearly described in natural language to ensure a common understanding by all involved, of the numerical score. As for independence of the criteria, it is difficult to ensure, as in many decision problems (Carlsson, Fullér 1995). What is important is that the criteria within a given dimension are independent, a condition that we took into account in the criteria definition phase.

Once the criteria have been defined, we begin by assessing the situation, current and future, in the absence of any remedial action. This future situation, called the natural evolution scenario (NES), is compared later with action based scenarios. Components of the real estate park are evaluated in collaboration with the expert technicians and the housing manager using the multi-criteria assessment method in Taillandier et al. (2009a).

The next step in system modeling is the evaluation of the impact of potential actions on each criterion quantified by the potential increase in the criterion's score following the action's implementation. This subjective assessment task is entrusted to technical experts who have a good knowledge of the housing stock. For example, given three criteria (security, availability and environment), the experts can assert that the renovation of the elevator in a building will increase the score of that building for the availability and security criteria while having no effect on the environment criterion. 


\subsubsection{Local perspective - interactive filtering of actions}

In the second phase, the decision maker may identify local objectives that are important to him. Actions are then selected to meet his goals and subsequently, an initial scenario (called initial partial scenario) is constructed using these actions. Two types of local filters may be proposed:

- Selection filters to retain actions that respond to an emergency, or that implement the strategy that seems particularly relevant in the context;

- Exclusion filters to exclude actions that are irrelevant to the strategy of the decision maker.

Filters are based on the score and on actions costs and allow the scheduling of actions in time. A local filter is defined by the following:

- Element affected by the filter (building, area...);

- Filtering criterion;

- Operator used for comparison with a value $(>,=\ldots)$;

- Threshold used in the filtering $(3,100 \mathrm{k€ \ldots} .$.$) ;$

- The first year to which the filtering condition applies.

If a goal on a criterion cannot be reached either for financial reasons or for the lack of sufficient actions, the decision maker is alerted and actions that allow him to get as close as possible to the goal are selected. He can, at any moment, rewind and modify previously defined filters. He can also identify the actions he does not wish to implement for various reasons. For example, he may wish, for strategic reasons, to exclude all actions on a given building if he deems that this building is not a priority.

The process of selection begins by retaining the actions relevant to the goal on a given criterion. It might be the case that several actions have to be used simultaneously in order to meet the objective. As an example, if a building has a score of 1 on a criterion, more than one action could be necessary to achieve a score of 3 if an individual action can only increase the score by 1 . It may also happen that several different actions (or a group of actions) allow the attainment of a goal. In this case, the actions retained are the ones with the smallest cost.

The next step is to schedule the retained actions. The idea is to place them as late in time as possible while meeting the constraints and set goals. The first years are normally reserved to address emergencies.
When the total cost of actions selected by the chosen filters exceeds the global financial envelop available, two choices are possible: either to modify the financial constraint or to accept a compromise solution. A compromise solution is obtained by removing previously selected actions. To decide which action to remove, we compute the contribution of each selected action to the attainment of the goal on the associated building by formula (1) where we make the assumptions that the score's scale is actually an interval scale.

$$
Y(A)=\frac{\sum_{j \in Y e a r} \min (S w a, O b j)-S o a}{C o(A)},
$$

where: $\operatorname{Co}(A)$ - cost of action $A$; $S w a(j)$ - score of the considered building in year $j$ with action $A$; Soa(j) - score of the considered building in year $j$ without action $A ; O b j$ - goal value of the objective as provided by the decision maker.

The action A' with the lowest impact on the objective is removed; this is characterized by the smallest score $\mathrm{Y}\left(\mathrm{A}^{\prime}\right)$. If removing action $\mathrm{A}^{\prime}$ is not sufficient to comply with the financial constraints, the action with the second lowest impact is removed and so on. If the cost in a single year of selected actions exceeds the constraint on that year, we use a similar process, except that, instead of removing actions we bring them forward in time. However, if the action is already scheduled in the first year, it has to be removed.

A filter operates on a single field, a single operator and a single value. Yet it may be necessary sometimes to consider several fields simultaneously. We may wish for example to keep the actions that meet two pressing needs (e.g. regulatory compliance and client satisfaction). It is possible with the same filtering logic to handle such cases. The decision maker can also use filters in cascade (lexicographic filtering) in which case actions go through a first filter; the remaining actions are then submitted to the second filter and so on. The scheduling in time of actions can take place once the whole filtering cascade has been completed.

The scheduled actions correspond to the initial partial scenario around which a global set of scenarios is constructed in the optimization phase.

\subsubsection{Optimization - construction of a good set of scenarios}

The optimization phase leads to the development of a complete set of scenarios based on the initial partial scenario obtained during the local phase, to which different combinations of unscheduled 
and un-excluded actions are added. It is always possible to skip the local phase and go directly to optimization phase if the housing manager has no specific local goals that he wishes to achieve; in this case, the initial partial scenario is empty.

Scenario building is a combinatorial problem where all the feasible scenarios that meet the annual and global financial constraints are created such that:

- All the actions scheduled at the local level are present in the scenario at the scheduled year;

- Actions excluded at the local level are not included in a scenario.

The exhaustive enumeration of all the scenarios is not feasible in most cases. In fact, due to the combinatorial explosion, the total number of possible scenarios can quickly become extremely important. Let $\mathrm{Nb}_{\text {actions, }}$, be the number of actions and $\mathrm{Nb}_{\text {years, }}$ the number of years: the number of possible scenarios is $\mathrm{Nb}_{\text {years }}$ Nbactions (if no constraints are taken into account). Assuming that we have 30 actions and three years, we get more than $2 \times 10^{14}$ scenarios. Obviously, the constraints will allow, in most cases to limit the number of possible scenarios. However, unless we have very restrictive constraints, they will not decrease the solutions space enough to allow for the manual exploration of all the feasible scenarios. It is therefore necessary to use another strategy to support the decision maker. We propose to build a set of "good" scenarios using optimisation. But what is a good scenario and how do we find one?

\section{Scenario assessment}

In order to select good scenarios, a performance criterion must be defined that incorporates the decision maker's expectations. Therefore, for each criterion and each building, an "ideal" score and an "acceptable" one are identified. The ideal score is one that is "nice to have" and the acceptable score is one deemed satisfactory. Using these scores, an index that determines how close a scenario is to the expectations, is defined by formula (2) such that for all criteria, all years, and all buildings, $S(j, k, m) \geq \operatorname{IS}(k, m)$. Where: $I S(k, m)$ - ideal score for criterion $k$ and building $m ; A S(k, m)$ - acceptable score for criterion $k$ and building $m ; S(j, k, m)$ score of year $j$ on the criterion $k$ for building $m$.
An INAD value of 0 represents a perfect match between the scenario and the expectations. The lower the value of INAD the better is a scenario. It is clear that this is a compensatory index such that a good attainment of the goal on one criterion can compensate for a weak attainment on another criterion; there is also a compensation effect between buildings. The absence of weights means that all the criteria and all the buildings have the same relative importance.

\section{Construction of a set of good scenarios}

The next step is to construct a set of good scenarios, i.e. a set of scenarios that minimize the $I N A D$ index, used as an objective function. The optimization problem we have is a combinatorial problem where the size of the search space, that is to say the number of scenarios that can be built, is extremely large. It is therefore not possible to use complete search methods to find the global optimum. Instead, we propose to use a metaheuristic approach to find a set of good scenarios with a small INAD.

A metaheuristic is a strategy to guide the search for optimal solutions that is customized to the problem at hand. The solutions returned by a metaheuristic may not be optimal because of the incompleteness of the approach: The approaches based on metaheuristics usually only visit a very small part of the search space. Blum and Roli (2003) classify metaheuristics into two groups: those based on trajectories and those based on a population. Trajectories-based metaheuristics are single solution approaches: they start from an initial solution and try to improve it by successive movements in the solutions space. These include simulated annealing (Kirkpatrick et al. 1983), Tabu search (Glover 1986) or variable neighborhood search (Mladenović, Hansen 1997). Metaheuristics based on a population take into account many possible solutions at each iteration. The three main approaches in this field are particle swarm optimization (Kennedy, Eberhart 1995; Poli 2008), genetic algorithms (Elsayed et al. 2011; Holland 1975) and ant colony optimization (Dorigo et al. 2006; Yang, Zhuang 2010). We chose to use the reactive Tabu search (Battiti, Tecchiolli 1994). This method has been successfully applied to solve many problems (Battiti, Protasi 2001; Castellani

$$
I N A D(\text { Scenario })=\sum_{\mathrm{k} \in \text { Criteria }} \sum_{j \in \text { Years }} \sum_{m \in \text { Buildings }} \operatorname{Max}(0 ; \mathrm{IS}(\mathrm{k}, \mathrm{m})-\mathrm{S}(\mathrm{j}, \mathrm{k}, \mathrm{m}))+\operatorname{Max}(0 ; \mathrm{AS}(\mathrm{k}, \mathrm{m})-\mathrm{S}(\mathrm{j}, \mathrm{k}, \mathrm{m})) .
$$


et al. 2007; Taillandier, Drogoul 2008; Zhang et al. 2009) and is an improvement over Tabu search. The underlying principle is to start from an initial solution (a financially feasible scenario) and to improve it by exploring its neighborhood, defined as the set of financially feasible slightly different solutions in terms of four basic variations:

- The addition of a new action in a given year to the scenario;

- The deletion of an action in the scenario;

- The replacement of an action by another one that is not in the scenario;

- The change of the implementation year in a scenario.

The use of a reactive Tabu search allows us to explore the search space starting from a given initial solution. To explore more widely the space of possible scenarios, we launch the search algorithm 20 times after having constructed a random set of initial solutions. The algorithm is stopped after 5 minutes. We retain all the solutions that have an $I N A D$ value within less than $5 \%$ of the smallest (best) INAD value.

Like for all meta-heuristics, the use of the reactive Tabu search requires to define several parameter values. However, one of the interests of the reactive Tabu search in addition to its efficiency is its robustness toward the parameter values (Battiti, Tecchiolli 1994). All the experiments carried out are along the line this statement and showed that for our application the parameter values of the reactive Tabu search had little impact on the results, but a deeper study is needed.

Global perspective - selection of the "optimal" scenario

Starting from the set of good scenarios obtained during the optimization phase, the aim is to determine the best scenario, using global filters defined by the decision maker. These filters operate in a similar fashion to the local filters. The difference is that, on the global level, we filter scenario instead of actions. Global filters may be defined on an objective to reach (e.g. "ensure a sufficient client satisfaction until 2011") or on the global structure of the scenario (e.g. "limit the number of actions on a same building in a year"). At the end of this phase, the single remaining scenario constitutes the solution, the final action plan that will be implemented.

\section{APPLICATION}

The REMIND method was implemented in a prototype and applied in an experiment conducted in collaboration with a leading French company. This company's housing stock is composed of several hundred buildings, some of which are located on a single site. We considered 92 buildings for a net floor area of around $300,000 \mathrm{~m}^{2}$. The company is structured around four main stakeholders' types: technicians, technical managers, area managers and a real estate property manager (the decision maker). The company employs a sufficient number of technical experts which allows it to assess and maintain buildings in an autonomous fashion. We illustrate the workings of REMIND using a case study conducted within this company.

\subsection{System modeling and components assessment}

The definition of the system elements correspond to the description of the components of the real estate park as illustrated in Figure 3 with five areas and a total of 92 buildings. The experimentation was done on the five areas, but we focus on Area 1 (22 buildings), the most strategic area. The choice to consider one area at a time is due to the organization of the housing stock department for which each area is considered separately.

A five year time horizon was considered (2009 to 2013) with two levels of financial constraints: a global constraint (for the five years) corresponding to a total amount of 4,000 $\mathrm{k} €$ and an annual constraint corresponding to an amount of 1,000 k€.

In conjunction with the decision maker, criteria and their associated measurement scales were

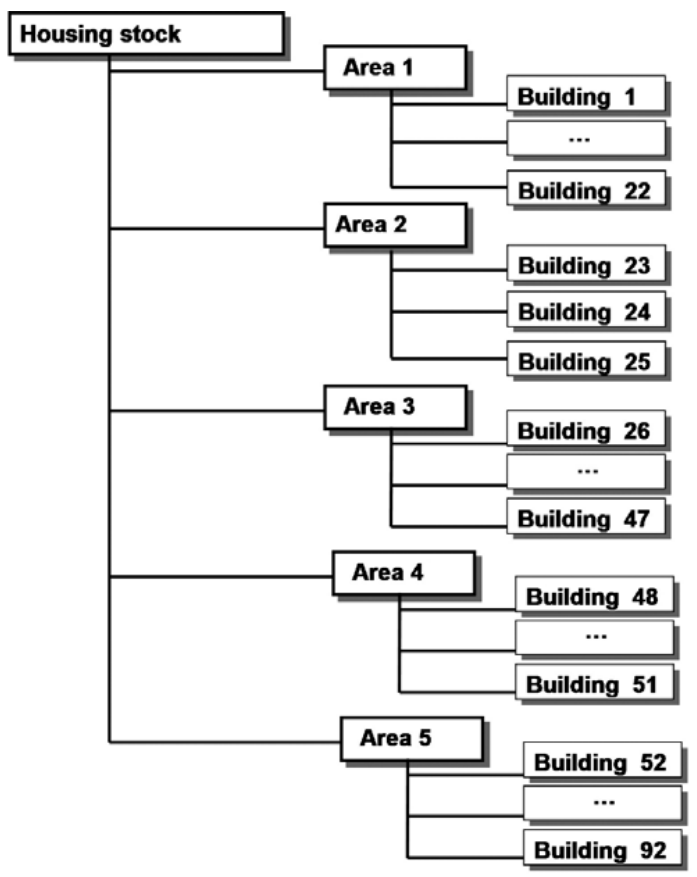

Fig. 3. System elements 
Table 1. Natural evolution scenario

\begin{tabular}{|c|c|c|c|c|c|c|c|c|c|c|c|c|c|c|c|}
\hline & 2009 & & & 2010 & & & 2011 & & & 2012 & & & 2013 & & \\
\hline Building & $\mathrm{CON}$ & AVA & $\mathrm{SAT}$ & $\mathrm{CON}$ & AVA & $\mathrm{SAT}$ & $\mathrm{CON}$ & AVA & $\mathrm{SAT}$ & $\mathrm{CON}$ & AVA & $\mathrm{SAT}$ & $\mathrm{CON}$ & AVA & $\mathrm{SAT}$ \\
\hline B1 & 3 & 2 & 2 & 3 & 2 & 2 & 3 & 2 & 2 & 2 & 2 & 2 & 2 & 2 & 2 \\
\hline B2 & 3 & 2 & 2 & 3 & 2 & 2 & 3 & 2 & 2 & 2 & 2 & 2 & 2 & 1 & 2 \\
\hline B3 & 3 & 4 & 4 & 3 & 3 & 3 & 3 & 2 & 2 & 3 & 2 & 2 & 3 & 2 & 2 \\
\hline B4 & 3 & 2 & 2 & 3 & 1 & 2 & 3 & 1 & 2 & 3 & 1 & 1 & 3 & 1 & 1 \\
\hline B5 & 2 & 1 & 2 & 2 & 1 & 2 & 2 & 1 & 2 & 2 & 1 & 2 & 2 & 1 & 2 \\
\hline $\mathrm{B} 6$ & 3 & 2 & 2 & 3 & 2 & 2 & 3 & 2 & 2 & 2 & 2 & 2 & 2 & 2 & 2 \\
\hline B7 & 3 & 2 & 1 & 3 & 2 & 1 & 3 & 2 & 1 & 3 & 2 & 1 & 3 & 2 & 1 \\
\hline B8 & 3 & 1 & 2 & 3 & 1 & 2 & 3 & 1 & 2 & 3 & 1 & 2 & 3 & 1 & 2 \\
\hline B9 & 3 & 2 & 2 & 3 & 2 & 2 & 3 & 2 & 2 & 3 & 2 & 2 & 3 & 1 & 2 \\
\hline B10 & 2 & 2 & 2 & 2 & 2 & 2 & 2 & 2 & 1 & 2 & 2 & 1 & 2 & 2 & 1 \\
\hline B11 & 2 & 2 & 2 & 2 & 2 & 2 & 2 & 2 & 2 & 2 & 2 & 2 & 2 & 2 & 2 \\
\hline B12 & 2 & 2 & 2 & 2 & 2 & 2 & 2 & 2 & 2 & 2 & 2 & 2 & 2 & 1 & 1 \\
\hline B13 & 2 & 2 & 2 & 2 & 2 & 2 & 2 & 2 & 2 & 2 & 1 & 2 & 2 & 1 & 2 \\
\hline B14 & 3 & 3 & 2 & 3 & 3 & 2 & 3 & 2 & 2 & 3 & 2 & 2 & 3 & 2 & 2 \\
\hline B15 & 3 & 2 & 1 & 3 & 2 & 1 & 3 & 2 & 1 & 3 & 2 & 1 & 3 & 2 & 1 \\
\hline B16 & 3 & 1 & 1 & 3 & 1 & 1 & 3 & 1 & 1 & 3 & 1 & 1 & 3 & 1 & 1 \\
\hline B17 & 3 & 2 & 1 & 3 & 1 & 1 & 3 & 1 & 1 & 2 & 1 & 1 & 2 & 1 & 1 \\
\hline B18 & 1 & 2 & 2 & 1 & 2 & 2 & 1 & 2 & 2 & 1 & 2 & 2 & 1 & 2 & 2 \\
\hline B19 & 3 & 3 & 3 & 3 & 3 & 3 & 3 & 3 & 3 & 3 & 3 & 3 & 3 & 3 & 3 \\
\hline B20 & 1 & 2 & 1 & 1 & 1 & 1 & 1 & 1 & 1 & 1 & 1 & 1 & 1 & 1 & 1 \\
\hline B21 & 2 & 2 & 2 & 2 & 1 & 2 & 2 & 1 & 1 & 2 & 1 & 1 & 2 & 1 & 1 \\
\hline B22 & 2 & 2 & 2 & 2 & 2 & 2 & 2 & 1 & 2 & 2 & 1 & 1 & 2 & 1 & 1 \\
\hline
\end{tabular}

Table 2. Description of the meaning of a score

\begin{tabular}{llll}
\hline Conformity & Availability & Satisfaction \\
\hline 1 & Serious nonconformity & Building unavailable & Client very unsatisfied \\
The building does not comply with regula- & It is likely that the & The quality of the goods and services does \\
tions (legal, standards, professional rules, & building could not ful- & not correspond to the expected requirement. \\
etc.). This nonconformity could have seri- & fill its function. & There is a risk of discontent. Tenants may for- \\
ous consequences. & & mulate a claim and lodge a complaint. They \\
& & may move out.
\end{tabular}

2 Rather serious nonconformity

The building does not comply with regulations. This nonconformity could have rather serious consequences.

3 Nonconformity with no serious consequences

The building does not comply with regulations but the nonconformity could only imply non serious consequences.

4 Perfect conformity or no regulations linked to the action

Two possible situations:

- The regulations are perfectly respected.

- There are no regulations linked to this situation.
Important degraded

use

The building should fulfill its function, but potentially in poor conditions.

Slight degraded use The building should fulfill its function, but not in perfect conditions.

Value exceeded The building should fulfill its function in perfect conditions.

\section{Client not satisfied}

The quality of the goods and services does not correspond to the expected requirement. Tenants may express dissatisfaction and move out if no actions are taken to improve the situation.

Client only somewhat satisfied

The quality of the goods and services does not correspond exactly to the expected requirement. Tenants may express dissatisfaction.

\section{Client satisfied}

The quality of the goods and services corresponds exactly to the expected requirement. defined in order to assess the consequences of the various actions. In our experiment, three impact areas were identified: conformity (CON), availability (AVA) and satisfaction (SAT). Conformity $(\mathrm{CON})$ is related to respecting the laws and meeting the standards. It is often a predominant aspect, since the consequences can be extremely important in case of failing to conform. Building availability (AVA) concerns the capacity of a building to meet its functions (structural stability, heating, water supply...). Satisfaction (SAT) pertains to the service contracts signed with the clients. Indeed, the company's clients who use the buildings have very precise requirements and expectations. These three impact areas were identified following discussions with the housing stock management team members.

Table 1 shows the status quo scores of the buildings (NES) on a 1 to 4 scale, 4 describing the best situation and 1 the worst. These were evaluated 
in collaboration with the expert technicians and the decision maker using the multi-criteria assessment method in (Taillandier et al. 2009a). They reflect the expert opinions of the actors involved. Table 2 describes the actual meaning of a score on a 1 to 4 scale for each criterion.

In total, 56 possible actions were defined by the technical experts. For conciseness reasons, Table 3 shows evaluations of a subset of these possible actions in terms of how they can increase the score of the building, along with their costs. These subjective evaluations were provided by the experts. For example, the renovation of the electrical system in Building 1 (A1) will increase the score of that building by one unit of the CON and AVA criteria while having no effect on the SAT criterion.

Figure 4, shows how a one-action scenario consisting of A1 implemented in 2011 compares to the NES. We see that prior to 2011, the housing stock has the same score in the NES and in the scenario. In 2011, the value of the scenario is increased by 1 on the CON and AVA criteria. A situation that remains after 2011 although, due to degradation in time, the value on the CON criterion is expected to decrease in 2013 while the others remain constant.

\subsection{Local perspective - interactive filtering of actions}

We summarize in Table 4 the results of the local phase after five filters were used (three for selection, one for exclusion and one cascade) based on the set of possible actions (Table 3).

In order to illustrate the filtering process, consider for example, a filter (regulatory filter) designed to attain the objective "ensure a high regulatory compliance level for the entire housing stock", which corresponds to a minimum score of 3 on the CON criterion for all years. The filter may be defined as follows:

- Element: all buildings;

- Filtering criterion: CON;
- Operator: $\geq$;

- Value: 3;

- Year: all years.

The process of selection begins by retaining the actions relevant to the objective at hand, in this case, a minimum score of 3 for the CON criterion. In the regulatory filter example presented here, we consider actions that may be applied to buildings with a score of 1 or 2 in CON and that allow the decision maker to attain the goal value of 3 . Table 5 lists the actions selected by the regulatory filter and shows the scores of the buildings on the CON criterion if no action is implemented. Actions A2, A5 and A32 are not retained because of their cost when compared to the costs of A4, A7 and $\mathrm{A} 42$.

The next step is to schedule the retained actions. As an example, for B17, we must retain A45 since it is the only option, and we place it in the last feasible year, 2012. For B12, we retain A29 because it is the least expensive option and we place as late as possible, 2009. The total cost is $1,270 \mathrm{k} €$, $890 \mathrm{k} €$ for 2009 and $380 \mathrm{k} €$ for 2012, a feasible financial solution.

When the selected actions needed to attain the decision maker's goal are not financially feasible, we apply the procedure as described in subsection 1.2.2. To illustrate this procedure, Table 6 shows actions selected by a filter in order to attain a score of 3 in SAT on buildings B13 to B22 and all years with a remaining budget of $30 \mathrm{k} €, 640 \mathrm{k} €, 720$ $\mathrm{k} €, 500 \mathrm{k} €$ and $930 \mathrm{k} €$ for the years 2009, 2010, 2011, 2012 and 2013 respectively. We note that in 2012 , the selected actions have a total cost of 940 $\mathrm{k} €$ therefore exceeding the budget of $500 \mathrm{k} €$. We therefore bring forward to 2011 the action with the lowest $\mathrm{Y}(=0.012)$, A42. Since this is not sufficient, we also have to bring forward A43. Therefore, the 2012 budget is now respected (a cost of $490 \mathrm{k} €$ for a budget of $500 \mathrm{k} €$ ). In 2011, we have a total cost of scheduled actions of $450 \mathrm{k} €$ (A42 and A43) versus

Table 3. Set of possible actions and their evaluation on the three criteria

\begin{tabular}{|c|c|c|c|c|c|c|}
\hline Action & Name & Building & $\mathrm{CON}$ & AVA & SAT & Cost $(\mathrm{k} €)$ \\
\hline A1 & Electrical system renovation & B1 & +1 & +1 & & 100 \\
\hline $\mathrm{A} 2$ & Water system renovation & B1 & +1 & & +1 & 150 \\
\hline A3 & Insulation addition & B1 & & & +2 & 80 \\
\hline $\mathrm{A} 4$ & Change of fire alarm & $\mathrm{B} 2$ & +1 & & & 120 \\
\hline A5 & Change of elevators & $\mathrm{B} 2$ & +1 & +1 & +1 & 200 \\
\hline A6 & Electrical system renovation & B3 & +1 & +1 & & 140 \\
\hline A7 & Fire door renovation & B3 & +1 & & & 40 \\
\hline A8 & Beams Reinforcement & B4 & +1 & +1 & & 100 \\
\hline A9 & Elevator renovation & B4 & & +2 & +1 & 120 \\
\hline $\mathrm{A} 10$ & Electrical system renovation & B5 & +2 & +1 & & 150 \\
\hline TOTAL & & & & & & 6640 \\
\hline
\end{tabular}


a budget of $720 \mathrm{k} €$. Finally actions A37, A38, A47, A51 and A56 are scheduled in 2012 and actions A42 and A43 are scheduled in 2011.

Two filters in cascade were used to reflect the goal of improving asset value (SAT) at the lowest cost, as follows:

Filter 1:

- Element: All buildings;

- Filtering criterion: AVA;

- Operator: $\geq$;

- Value: 2;

- Year: all years.

Filter 2:

- Element: All buildings;

- Filtering criterion: Action Cost;

- Operator: <;

- Value: 150 k€;

- Year: all years.

With these filters, we retain actions that have a cost lower than $150 \mathrm{k} €$ and that allow us to reach a score of 2 or higher on asset value. Table 7 presents the selected actions. As a result of this cascade filter, the following actions are scheduled: A8, A44, A49 and A52 in 2010, A35 in 2012, A22 and A33 in 2013.

Table 4. Local filters used

\begin{tabular}{|c|c|c|c|}
\hline Filters & Characteristic & Selected actions & Remaining budget ( $\mathrm{k} €$ ) in \\
\hline $\begin{array}{l}\text { Ensure a high } \\
\text { regulatory } \\
\text { compliance } \\
\text { level for the } \\
\text { entire housing } \\
\text { stock }\end{array}$ & $\begin{array}{l}\text { Selection } \\
\text { All buildings } \\
\text { All years } \\
\text { CON } \geq 3\end{array}$ & $\begin{array}{l}\text { 2009: } \mathrm{A} 23, \mathrm{~A} 27, \mathrm{~A} 29, \mathrm{~A} 34, \mathrm{~A} 46, \mathrm{~A} 50, \mathrm{~A} 54, \mathrm{~A} 55 \\
\text { 2010: } \\
\text { 2011: } \\
\text { 2012: } \mathrm{A} 1, \mathrm{~A} 4, \mathrm{~A} 45 \\
\text { 2013: }\end{array}$ & $\begin{array}{l}\text { 2009: } 110 \\
\text { 2010: } 1000 \\
\text { 2011: } 1000 \\
\text { 2012: } 620 \\
\text { 2013: } 1000 \\
\text { Global: } 2730\end{array}$ \\
\hline $\begin{array}{l}\text { Provide a high } \\
\text { service quality } \\
\text { in buildings in } \\
\text { B10 starting in } \\
2011\end{array}$ & $\begin{array}{l}\text { Selection } \\
\text { B12 } \\
2011 \\
\text { SAT }=4\end{array}$ & $\begin{array}{l}\text { 2009: A23, A27, A29, A34, A46, A50, A54, A55 } \\
\text { 2010: } \\
\text { 2011: } \mathrm{A} 25, \mathrm{~A} 26 \\
\text { 2012: } \mathrm{A} 1, \mathrm{~A} 4, \mathrm{~A} 45 \\
\text { 2013: }\end{array}$ & $\begin{array}{l}\text { 2009: } 110 \\
\text { 2010: } 1000 \\
\text { 2011: } 810 \\
\text { 2012: } 620 \\
\text { 2013: } 1000 \\
\text { Global: } 2540\end{array}$ \\
\hline $\begin{array}{l}\text { Not a priority: } \\
\text { Building } 8\end{array}$ & $\begin{array}{l}\text { Exclusion } \\
\text { B8 }\end{array}$ & Exclusion : A17, A18, A19 & Excluded Actions: 440 \\
\hline $\begin{array}{l}\text { Improve asset } \\
\text { value at the } \\
\text { lowest cost. }\end{array}$ & $\begin{array}{l}\text { Cascade filter } \\
\text { Filter } 1 \\
\text { Selection } \\
\text { All buildings } \\
\text { All years } \\
\text { AVA } \geq 2 \\
\text { Filter } 2 \\
\text { Selection } \\
\text { All buildings } \\
\text { All years } \\
\text { Action Cost }<150 \mathrm{k} €\end{array}$ & $\begin{array}{l}\text { 2009: A23, A27, A29, A34, A46, A50, A54, A55 } \\
\text { 2010: } \mathrm{A} 8, \mathrm{~A} 44, \mathrm{~A} 49, \mathrm{~A} 52 \\
\text { 2011: } \mathrm{A} 25, \mathrm{~A} 26 \\
\text { 2012: A1, A4, } \mathrm{A} 35, \mathrm{~A} 45 \\
\text { 2013: } \underline{\mathrm{A} 22, \mathrm{~A} 33}\end{array}$ & $\begin{array}{l}\text { 2009: } 110 \\
\text { 2010: } 560 \\
\text { 2011: } 810 \\
\text { 2012: } 500 \\
\text { 2013: } 790 \\
\text { Global: } 1770\end{array}$ \\
\hline $\begin{array}{l}\text { Reach a high } \\
\text { client satisfac- } \\
\text { tion in } 2012 \text { for } \\
\text { buildings B13 } \\
\text { to B22 }\end{array}$ & $\begin{array}{l}\text { Selection } \\
\text { B13-B22 } \\
2012 \\
\text { SAT } \geq 3\end{array}$ & $\begin{array}{l}\text { 2009: A23, A27, A29, A34, A46, A50, A54, A55 } \\
\text { 2010: A8, A44, A49, A52 } \\
\text { 2011: A25, A26, } \mathrm{A} 42, \mathrm{~A} 43 \\
\text { 2012: A1, A4, A35, } \underline{\mathrm{A} 37, \mathrm{~A} 38}, \mathrm{~A} 45, \underline{\mathrm{A} 47, \mathrm{~A} 51, \mathrm{~A} 56} \\
\text { 2013: } \mathrm{A} 22, \mathrm{~A} 33\end{array}$ & $\begin{array}{l}\text { 2009: } 110 \\
\text { 2010: } 560 \\
\text { 2011: } 360 \\
\text { 2012: } 90 \\
\text { 2013: } 790 \\
\text { Global: } 830\end{array}$ \\
\hline
\end{tabular}


Table 5. Actions retained by the regulatory filter

\begin{tabular}{|c|c|c|c|c|c|c|c|c|c|c|c|c|c|}
\hline \multirow[t]{2}{*}{ Action } & \multirow[t]{2}{*}{ Building } & \multirow[t]{2}{*}{ Impact on $\mathrm{CON}$} & \multicolumn{5}{|c|}{ CON before action } & \multicolumn{5}{|c|}{ CON after action } & \multirow[t]{2}{*}{ Cost } \\
\hline & & & 2009 & 2010 & 2011 & 2012 & 2013 & 2009 & 2010 & 2011 & 2012 & 2013 & \\
\hline $\mathrm{A} 1$ & B1 & 1 & 3 & 3 & 3 & $\underline{2}$ & $\underline{2}$ & 4 & 4 & 4 & 3 & 3 & 100 \\
\hline $\mathrm{A} 2$ & B1 & 1 & 3 & 3 & 3 & $\underline{2}$ & $\underline{2}$ & 4 & 4 & 4 & 3 & 3 & 150 \\
\hline $\mathrm{A} 4$ & $\mathrm{~B} 2$ & 1 & 3 & 3 & 3 & $\underline{2}$ & $\underline{2}$ & 4 & 4 & 4 & 3 & 3 & 120 \\
\hline A5 & $\mathrm{B} 2$ & 1 & 3 & 3 & 3 & $\underline{2}$ & $\underline{2}$ & 4 & 4 & 4 & 3 & 3 & 200 \\
\hline $\mathrm{A} 23$ & B10 & 1 & $\underline{2}$ & $\underline{2}$ & $\underline{2}$ & $\underline{2}$ & $\underline{2}$ & 3 & 3 & 3 & 3 & 3 & 60 \\
\hline A 27 & B11 & 1 & $\underline{2}$ & $\underline{2}$ & $\underline{2}$ & $\underline{2}$ & $\underline{2}$ & 3 & 3 & 3 & 3 & 3 & 180 \\
\hline A29 & B12 & 1 & $\underline{2}$ & $\underline{2}$ & $\underline{2}$ & $\underline{2}$ & $\underline{2}$ & 3 & 3 & 3 & 3 & 3 & 70 \\
\hline A32 & B12 & 1 & $\underline{2}$ & $\underline{2}$ & $\underline{2}$ & $\underline{2}$ & $\underline{2}$ & 3 & 3 & 3 & 3 & 3 & 110 \\
\hline A34 & B13 & 2 & $\underline{2}$ & $\underline{2}$ & $\underline{2}$ & $\underline{2}$ & $\underline{2}$ & 4 & 4 & 4 & 4 & 4 & 160 \\
\hline A 45 & B17 & 1 & $\underline{3}$ & $\underline{3}$ & $\underline{3}$ & $\underline{2}$ & $\underline{2}$ & 4 & 4 & 4 & 3 & 3 & 160 \\
\hline A 46 & B18 & 2 & $\underline{1}$ & $\underline{1}$ & $\underline{1}$ & $\underline{1}$ & $\underline{1}$ & 3 & 3 & 3 & 3 & 3 & 90 \\
\hline A50 & B20 & 2 & $\underline{1}$ & $\underline{1}$ & 1 & 1 & $\underline{1}$ & 3 & 3 & 3 & 3 & 3 & 110 \\
\hline A54 & B21 & 2 & $\underline{2}$ & $\underline{2}$ & $\underline{2}$ & $\underline{2}$ & $\underline{2}$ & 4 & 4 & 4 & 4 & 4 & 130 \\
\hline A55 & B22 & 1 & $\underline{2}$ & $\underline{2}$ & $\underline{2}$ & $\underline{2}$ & $\underline{2}$ & 3 & 3 & 3 & 3 & 3 & 90 \\
\hline
\end{tabular}

Table 6. Example of filtering actions exceeding constraint on the year

\begin{tabular}{llll}
\hline Action & Year scheduled & Y(A) & Cost $(\mathrm{k} €)$ \\
\hline A37 & 2012 & 0.067 & 30 \\
A38 & 2012 & 0.025 & 80 \\
A42 & 2012 & 0.012 & 170 \\
A43 & 2012 & 0.014 & 280 \\
A47 & 2012 & 0.015 & 130 \\
A51 & 2012 & 0.04 & 50 \\
A56 & 2012 & 0.033 & 120 \\
\hline
\end{tabular}

Table 7. Actions retained by the dual filter

\begin{tabular}{|c|c|c|c|c|c|c|c|c|c|c|c|c|c|}
\hline \multirow[t]{2}{*}{ Action } & \multirow[t]{2}{*}{ Building } & \multirow{2}{*}{$\begin{array}{l}\text { Impact on } \\
\text { AVA }\end{array}$} & \multicolumn{5}{|c|}{ AVA before action } & \multicolumn{5}{|c|}{ AVA after action } & \multirow{2}{*}{$\begin{array}{l}\text { Cost } \\
(\mathrm{k} €)\end{array}$} \\
\hline & & & 2009 & 2010 & 2011 & 2012 & 2013 & 2009 & 2010 & 2011 & 2012 & 2013 & \\
\hline A8 & $\mathrm{B} 4$ & 1 & 2 & 1 & 1 & 1 & 1 & 2 & 2 & 2 & 2 & 2 & 100 \\
\hline A 22 & B9 & 1 & 2 & 2 & 2 & 2 & 1 & 3 & 3 & 3 & 3 & 2 & 140 \\
\hline A33 & B12 & 1 & 2 & 2 & 2 & 2 & 1 & 3 & 3 & 3 & 3 & 2 & 70 \\
\hline A35 & B13 & 1 & 2 & 2 & 2 & 1 & 1 & 3 & 3 & 3 & 2 & 2 & 120 \\
\hline A 44 & B17 & 1 & 2 & 1 & 1 & 1 & 1 & 2 & 2 & 2 & 2 & 2 & 140 \\
\hline A 49 & $\mathrm{~B} 20$ & 1 & 2 & 1 & 1 & 1 & 1 & 2 & 2 & 2 & 2 & 2 & 80 \\
\hline A52 & B21 & 1 & 2 & 1 & 1 & 1 & 1 & 3 & 2 & 2 & 2 & 2 & 120 \\
\hline
\end{tabular}

Table 8. List of filters used in global phase

\begin{tabular}{lll}
\hline Filter & Characteristic & $\begin{array}{l}\text { Number of scenarios } \\
\text { remaining after filtering }\end{array}$ \\
\hline At the beginning of the global phase & & 300 \\
\hline Balance the actions on the five years & ActionCost.year $\geq 500 \mathrm{k} €$ & 123 \\
$\begin{array}{l}\text { Limit the number of actions on a same building in a } \\
\text { year }\end{array}$ & NbAction.Building.year<4 & 56 \\
Ensure adequate client satisfaction starting in 2011 & $\begin{array}{l}\text { SAT>1 } \\
\text { Every buildings 2011, 2012, 2013 } \\
\text { Prefer actions on B5 }\end{array}$ & 5 \\
\hline
\end{tabular}


Table 9. Final action plan to be implemented

\begin{tabular}{|c|c|c|c|c|c|c|}
\hline Actions & 2009 & 2010 & 2011 & 2012 & 2013 & Filter \\
\hline A3 & 80 & & & & & Global filters \\
\hline A23 & 60 & & & & & Ensure a high regulatory compliance level for the entire housing stock \\
\hline A27 & 180 & & & & & Ensure a high regulatory compliance level for the entire housing stock \\
\hline A29 & 70 & & & & & Ensure a high regulatory compliance level for the entire housing stock \\
\hline A34 & 160 & & & & & Ensure a high regulatory compliance level for the entire housing stock \\
\hline A46 & 90 & & & & & Ensure a high regulatory compliance level for the entire housing stock \\
\hline A50 & 110 & & & & & Ensure a high regulatory compliance level for the entire housing stock \\
\hline A5 54 & 130 & & & & & Ensure a high regulatory compliance level for the entire housing stock \\
\hline A55 & 90 & & & & & Ensure a high regulatory compliance level for the entire housing stock \\
\hline A8 & & 100 & & & & Improve asset value at the lowest cost \\
\hline A9 & & 120 & & & & Global filters \\
\hline A10 & & 150 & & & & Global filters \\
\hline A16 & & 120 & & & & Global filters \\
\hline A44 & & 140 & & & & Improve asset value at the lowest cost. \\
\hline A49 & & 80 & & & & Improve asset value at the lowest cost. \\
\hline A52 & & 120 & & & & Improve asset value at the lowest cost. \\
\hline A25 & & & 120 & & & Provide a high service quality in buildings in B10 starting in 2011 \\
\hline A26 & & & 70 & & & Provide a high service quality in buildings in B10 starting in 2011 \\
\hline A 42 & & & 170 & & & Reach a high client satisfaction in 2012 for buildings B13 to B22 \\
\hline A43 & & & 280 & & & Reach a high client satisfaction in 2012 for buildings B13 to B22 \\
\hline A53 & & & 80 & & & Global filters \\
\hline A1 & & & & 100 & & Ensure a high regulatory compliance level for the entire housing stock \\
\hline A4 & & & & 120 & & Ensure a high regulatory compliance level for the entire housing stock \\
\hline A35 & & & & 120 & & Improve asset value at the lowest cost \\
\hline A37 & & & & 30 & & Reach a high client satisfaction in 2012 for buildings B13 to B22 \\
\hline A38 & & & & 80 & & Reach a high client satisfaction in 2012 for buildings B13 to B22 \\
\hline A 45 & & & & 160 & & Ensure a high regulatory compliance level for the entire housing stock \\
\hline A47 & & & & 130 & & Reach a high client satisfaction in 2012 for buildings B13 to B22 \\
\hline A51 & & & & 50 & & Reach a high client satisfaction in 2012 for buildings B13 to B22 \\
\hline A56 & & & & 120 & & Reach a high client satisfaction in 2012 for buildings B13 to B22 \\
\hline A13 & & & & & 90 & Global filters \\
\hline A14 & & & & & 80 & Global filters \\
\hline A21 & & & & & 160 & Global filters \\
\hline A 22 & & & & & 140 & Improve asset value at the lowest cost \\
\hline A33 & & & & & 70 & Improve asset value at the lowest cost \\
\hline Total (k€) & 970 & 830 & 720 & 910 & 540 & 3970 \\
\hline
\end{tabular}

The scheduled actions correspond to the initial partial scenario around which a global set of scenarios are constructed in the optimization phase.

\subsection{Optimization - construction of a good set of scenarios}

The first step in the optimization phase is to define acceptable and ideal scores in order to build a set of good scenarios. We use the same values for all buildings where we set an ideal score of 4 for the three dimensions of conformity, availability and satisfaction, and acceptable scores of 3, 2, 2 , respectively. The INAD index for SEN is 808, whereas that of the initial partial scenario is 539 . The next step is to construct a set of good scenarios. In this experimentation, the best INAD value found was 463. We therefore kept all the solutions with an INAD value inferior to 486 . A set of 300 feasible scenarios were thus found and constitute the set of good scenarios. The action plan to be implemented was finally chosen among these 300 feasible scenarios using four global filters (Table 8). This solution is presented in Table 9.

\section{CONCLUSION}

In this paper, we have presented and described REMIND, a novel interactive decision support method for the strategic management of real estate properties based on multiple criteria, namely conformity to rules and regulations, availability of a building's function and satisfaction of the cli- 
ent. REMIND is meant to assist a housing stock manager in the progressive design and choice of a multiyear action plan and is composed of four main phases including an optimization phase that uses reactive Tabu search.

REMIND allows a building stock manager to choose various improvement actions to his building stock, schedule them into scenarios that are financially feasible and select the best action plan. It was successfully applied within a leading French property management company where it was deemed useful and pertinent, mainly because it supports the dialogue between the decision maker and other stakeholders. The choice of every action is justified by filters, thereby making the decisions easily traceable. This is a very important point for many decision makers who sometimes feel that some decision support methods are not very transparent (Pfeffer, Sutton 2006).

One advantage of the interactive approach is that preferences are expressed interactively instead of a priori and that the decision maker remains at the heart of the decision process, steering it and, through the simulation process, acquiring a clear understanding of the various impacts of his choices. Although developed for the real estate context, the approach combining simulation and optimisation may be used for planning in other application areas.

\section{REFERENCES}

Bana e Costa, C. A. 1986. A multicriteria decision aid methodology to deal with conflicting situations on the weights, European Journal of Operational Research 26(1): 22-34. http://dx.doi.org/10.1016/03772217(86)90156-6

Battiti, R.; Protasi, M. 2001. Reactive local search for the maximum clique problem, Algorithmica 29(4): 610-637. http://dx.doi.org/10.1007/s004530010074

Battiti, R.; Tecchiolli, G. 1994. The reactive tabu search, ORSA Journal on Computing 6(2): 126-140. http:// dx.doi.org/10.1287/ijoc.6.2.126

Blum, C.; Roli, A. 2003. Metaheuristics in combinatorial optimization: overview and conceptual comparison, ACM Computing Surveys 35(3): 268-308. http:// dx.doi.org/10.1145/937503.937505

Bonetto, R.; Sauce, G. 2006. Gestion du patrimoine immobilier - Les activités de références, Vol. 1. (CSTB ed).

Bouyssou, D. 1993. Décision multicritère ou aide multicritère?, in Newsletter of the European working group "Multicriteria aid for decisions".

Carlsson, C.; Fullér, R. 1995. Multiple criteria decision making: the case for interdependence, Computers \& Operations Research 22(3): 251-260. http://dx.doi. org/10.1016/0305-0548(94)E0023-Z
Castellani, U.; Fusiello, A.; Gherardi, R.; Murino, V. 2007. Automatic selection of MRF control parameters by reactive tabu search, Image and Vision Computing 25(11): 1824-1832. http://dx.doi.org/10.1016/j. imavis.2007.04.002

Climaco, J.; Craveirinha, J. 2005. Multicriteria analysis in telecommunication network planning and design problems and issues, in Multiple criteria decision analysis: state of the art surveys. New York: Springer, 899-941. http://dx.doi.org/10.1007/0-387-23081-5_22

Churchman, C. W.; Ackoff, R. L. 1954. An approximate measure of value, Journal of the Operations Research Society of America 2(2): 172-187. http://dx.doi. org/10.1287/opre.2.2.172

Diakoulaki, D.; Antunes, C. H.; Martins, A. G. 2005. MCDA and energy planning, in Multiple criteria decision analysis: state of the art surveys. New York: Springer, 859-890. http://dx.doi.org/10.1007/0-38723081-5_21

Dorigo, M.; Birattari, M.; Stutzle, T. 2006. Ant colony optimization, Computational Intelligence Magazine, IEEE 1(4): 28-39. http://dx.doi.org/10.1109/ MCI.2006.329691

Elsayed, S. M.; Sarker, R. A.; Essam, D. L. 2011. Multioperator based evolutionary algorithms for solving constrained optimization problems, Computers \& Operations Research 38(12): 1877-1896. http://dx.doi. org/10.1016/j.cor.2011.03.003

Gershon, M. 1984. The role of weights and scales in the application of multiobjective decision making, $E u$ ropean Journal of Operational Research 15(2): 244250. http://dx.doi.org/10.1016/0377-2217(84)90214-5

Glover, F. 1986. Future paths for integer programming and links to artificial intelligence, Computers \& Operations Research 13(5): 533-549. http://dx.doi. org/10.1016/0305-0548(86)90048-1

Hajkowicz, S.; Collins, K. 2007. A review of multiple criteria analysis for water resource planning and management, Water Resources Management 21(9): 15531566. http://dx.doi.org/10.1007/s11269-006-9112-5

Hites, R.; De Smet, Y.; Risse, N.; Salazar-Neumann, M.; Vincke, P. 2006. About the applicability of MCDA to some robustness problems, European Journal of Operational Research 174(1): 322-332. http://dx.doi. org/10.1016/j.ejor.2005.01.031

Holland, J. H. 1975. Adaptation in natural and artificial systems. University of Michigan Press.

Keeney, R. L.; Raiffa, H. 1976. Decisions with multiple objectives: preferences and value tradeoff. New York: Wiley.

Kennedy, J.; Eberhart, R. 1995. Particle swarm optimization, in Proceedings of the IEEE international conference on neural networks 4: 1942-1948. http:// dx.doi.org/10.1109/ICNN.1995.488968

Kirkpatrick, S.; Gelatt, C. D.; Vecchi, M. P. 1983. Optimization by simulated annealing, Science 220(4598): 671-680. http://dx.doi.org/10.1126/science.220.4598.671

Kodikara, P. N.; Perera, B. J. C.; Kularathna, M. D. U. P. 2010. Stakeholder preference elicitation and modelling in multi-criteria decision analysis - a case study on urban water supply, European Journal of 
Operational Research 206(1): 209-220. http://dx.doi. org/10.1016/j.ejor.2010.02.016

Korhonen, P. 2005. Interactive methods, in Multiple criteria decision analysis: state of the art surveys. New York: Springer, 641-661. http://dx.doi.org/10.1007/0387-23081-5_16

Miettinen, K.; Ruiz, F.; Wierzbicki, A. P. 2008. Introduction to multiobjective optimization: interactive approaches, Lecture Notes in Computer Science 5252: 27-57. http://dx.doi.org/10.1007/978-3-540-88908-3_2

Mladenović, N.; Hansen, P. 1997. Variable neighborhood search, Computers \& Operations Research 24(11): 1097-1100. http://dx.doi.org/10.1016/S03050548(97)00031-2

Montibeller, G.; Franco, L. A.; Lord, E.; Iglesias, A. 2009. Structuring resource allocation decisions: a framework for building multi-criteria portfolio models with area-grouped options, European Journal of Operational Research 199(3): 846-856. http://dx.doi. org/10.1016/j.ejor.2009.01.054

Munda, G. 2005. Multiple criteria decision analysis and sustainable development, in Multiple criteria decision analysis: state of the art surveys. York: Springer New, 953-986. http://dx.doi.org/10.1007/0-387-230815_23

Mustajoki, J.; Hämäläinen, R. P.; Sinkko, K. 2007. Interactive computer support in decision conferencing: two cases on off-site nuclear emergency management, Decision Support Systems 42(4): 2247-2260. http://dx.doi.org/10.1016/j.dss.2006.07.003

Narula, S. C.; Vassilev, V.; Genova, K.; Vassileva, M. 2003. Partition-based interactive method to solve discrete multicriteria choice problems, Cynerbetics and Information Technologies 3(2): 55-66.

Nickel, S.; Puerto, J.; Rodríguez-Chía, A. M. 2005. MCDM location problems, in Multiple criteria decision analysis: state of the art surveys. New York: Springer, 761-787. http://dx.doi.org/10.1007/0-38723081-5_19

Nowak, M. 2006. INSDECM - an interactive procedure for stochastic multicriteria decision problems, European Journal of Operational Research 175(3): 14131430. http://dx.doi.org/10.1016/j.ejor.2005.02.016

Pfeffer, J.; Sutton, R. I. 2006. Evidence-based management, Harvard Business Review 84: 62-74.

Phillips, L. D.; Bana e Costa, C. A. 2007. Transparent prioritisation, budgeting and resource allocation with multi-criteria decision analysis and decision conferencing, Annals of Operations Research 154(1): 51-68. http://dx.doi.org/10.1007/s10479-007-0183-3

Poli, R. 2008. Analysis of the publications on the applications of particle swarm optimisation, Journal of Artificial Evolution and Applications 2008: 1-10. http://dx.doi.org/10.1155/2008/685175

Roy, B. 1985. Méthodologie multicritère d'aide à la décision (Economica ed.). Paris.
Schärlig, A. 1985. Décider sur plusieurs critères, panorama de l'aide à la décision multicritère. Lausanne: Presses polytechniques et universitaires romandes.

Stewart, T. J.; Scott, L. 1995. A scenario-based framework for multicriteria decision analysis in water resources planning, Water Resources Research 31(11): 2835-2843. http://dx.doi.org/10.1029/95WR01901

Spronk, J.; Steuer, R. E.; Zopounidis, C. 2005. Multicriteria decision aid/analysis in finance, in Multiple criteria decision analysis: state of the art surveys. New York: Springer, 799-848. http://dx.doi.org/10.1007/0387-23081-5_20

Taillandier, F.; Abi-Zeid, I. 2013. A multicriteria evaluation of real estate properties based on environmental impacts, International Journal of Multicriteria Decision Making 3(4): 303-324. http://dx.doi.org/10.1504/ IJMCDM.2013.056778

Taillandier, F.; Sauce, G.; Bonetto, R. 2009a. Apology of the risk as the key to drive the real-estate, in International conference on Industrial Engineering and Systems Management (IESM), 13-15 May. 2009, Montreal, Canada.

Taillandier, F.; Sauce, G.; Bonetto, R. 2009b. Riskbased investment trade-off related to building facility management, Reliability Engineering \& System Safety 94(4): 785-795. http://dx.doi.org/10.1016/j. ress.2008.09.005

Taillandier, P.; Drogoul, A. 2008. Knowledge revision in systems based on an informed tree search strategy: application to cartographic generalisation, in Proceedings of the 5th international conference on Soft computing as transdisciplinary science and technology, 27-31 October, 2008, Cergy-Pontoise, Paris, France: ACM, 273-278. http://dx.doi. org/10.1145/1456223.1456281

Trinkaus, H. L.; Hanne, T. 2005. knowCube: a visual and interactive support for multicriteria decision making, Computers \& Operations Research 32(5): 1289-1309. http://dx.doi.org/10.1016/j.cor.2003.11.010

Vansnick, J.-C. 1986. On the problem of weights in multiple criteria decision making (the noncompensatory approach), European Journal of Operational Research 24(2): 288-294. http://dx.doi.org/10.1016/03772217(86)90051-2

Yang, J.; Zhuang, Y. 2010. An improved ant colony optimization algorithm for solving a complex combinatorial optimization problem, Applied Soft Computing 10(2): 653-660. http://dx.doi.org/10.1016/j. asoc.2009.08.040

Yeh, C.-H.; Willis, R. J.; Deng, H.; Pan, H. 1999. Task oriented weighting in multi-criteria analysis, European Journal of Operational Research 119(1): 130146. http://dx.doi.org/10.1016/S0377-2217(98)90353-8

Zhang, R.; Yun, W. Y.; Moon, I. 2009. A reactive tabu search algorithm for the multi-depot container truck transportation problem, Transportation Research Part E: Logistics and Transportation Review 45(6): 904-914. http://dx.doi.org/10.1016/j.tre.2009.04.012 